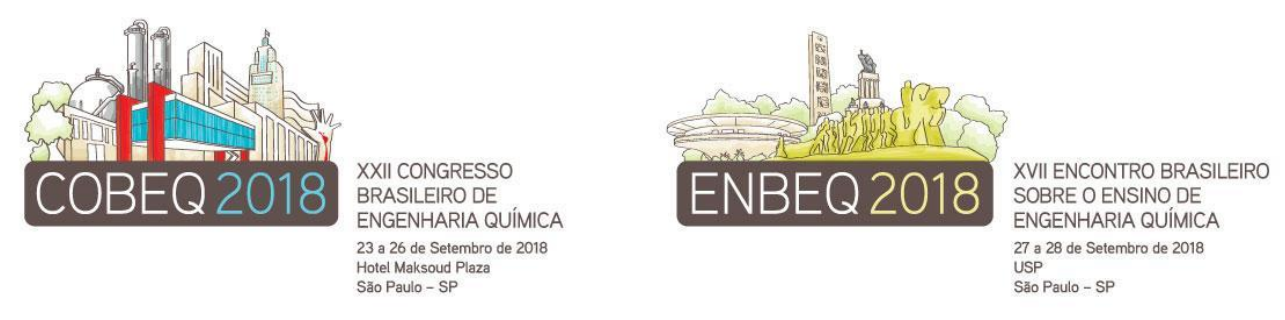

\title{
TRATAMENTO DO EFLUENTE GERADO NA PRODUÇÃO DO BIODIESEL POR MEIO DA REAÇÃO DE FENTON HETEROGÊNEA COM RESÍDUO SIDERÚRGICO
}

\author{
FÉLIX JSAO ${ }^{1}$, ALVES LF $^{1}$, XAVIER IPAS $^{1}$ e CASTRO FD ${ }^{1}$ \\ ${ }^{1}$ Centro Universitário do Leste de Minas Gerais, Departamento de Engenharia Química \\ E-mail para contato: jamyla_soares@ hotmail.com
}

\begin{abstract}
RESUMO - Neste trabalho, foi investigada a aplicação de resíduo siderúrgico como catalisador na reação de Fenton Heterogênea, visando degradar a matéria orgânica presente em águas de lavagem da produção de biodiesel. Os experimentos foram realizados em batelada, à temperatura ambiente, meio ácido ( $\mathrm{pH} 2,88 \pm 0,07)$, mantendo-se fixa a concentração do resíduo $(2 \mathrm{~g} / \mathrm{L})$. Investigou-se a influência da concentração de peróxido de hidrogênio (500, 250 e $100 \mathrm{mg} / \mathrm{L})$, na remoção da $D Q O$ das amostras tratadas. Verificou-se que a condição mais favorável de tratamento foi para $\left[\mathrm{H}_{2} \mathrm{O}_{2}\right]=250 \mathrm{mg} / \mathrm{L}$. Nessa condição, após 10 e 20 minutos de reação, foi possível alcançar, respectivamente, 92 e $95 \%$ na remoção da DQO.
\end{abstract}

\section{INTRODUÇÃO}

A forma convencional de obtenção do biodiesel consiste na reação de transesterificação, que ocorre entre os óleos vegetais, residuais ou gorduras animais e álcool (metanol ou etanol), na presença de um catalisador, geralmente alcalino, para formar biodiesel bruto e glicerina. A etapa de purificação do biodiesel gera grande volume de água de lavagem, numa proporção de até 1:3 (biodiesel: água de lavagem), que possui alta carga orgânica (Brito, 2015).

Os Processos Oxidativos Avançados (POA) baseiam-se na geração de radicais hidroxila, que são altamente reativos e destroem uma variedade de poluentes orgânicos. A reação de Fenton consiste em um conjunto de reações cíclicas, que utilizam íons de ferro como catalisadores para decompor o peróxido de hidrogênio e produzir radicais hidroxila, ocorrendo em condições ácidas (pH de 2,5 - 3,0) (Araújo, 2008).

Neste trabalho, foi investigada a reação de Fenton Heterogênea, utilizando como fonte de ferro resíduo sólido sem valor agregado, oriundo do processo siderúrgico. Optou-se pelo sistema heterogêneo para aproveitamento do resíduo e, pelo menor potencial de geração de lodo, se comparado ao sistema homogêneo.

\section{MATERIAIS E MÉTODOS}

O biodiesel foi produzido via catálise homogênea no Laboratório de Engenharia 


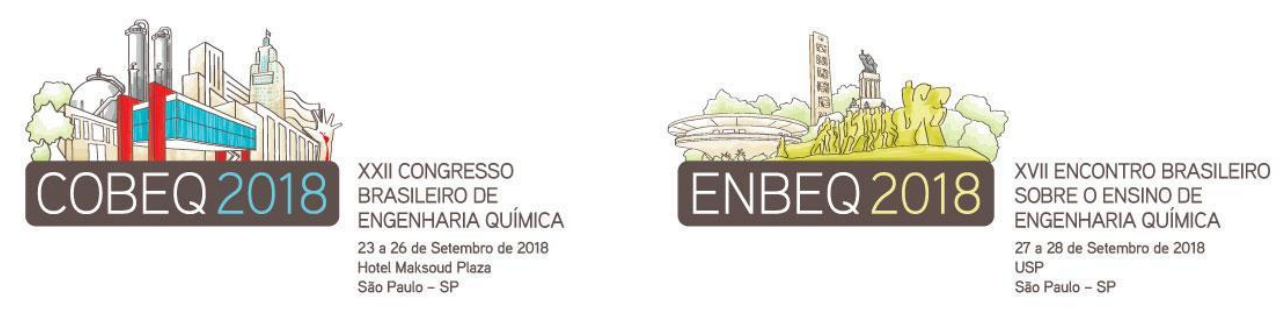

Química do Centro Universitário do Leste de Minas Gerais, em pequena escala, utilizando-se metanol, óleo residual de fritura e hidróxido de potássio $(\mathrm{KOH})$. O efluente utilizado no estudo corresponde às águas de lavagem aquosas posteriores à lavagem inicial.

Os estudos de oxidação avançada com reagente de Fenton foram realizados à temperatura ambiente, em reatores estáticos de bancada sob agitação constante, contendo 20 $\mathrm{mL}$ de efluente. Utilizou-se pó de minério Serra Azul (diâmetro <0,075 mm) como fonte de ferro para a reação, o qual foi cedido por uma indústria siderúrgica regional. A composição do resíduo foi fornecida pela indústria cedente (Tabela 1), e este permaneceu em dessecadora para remoção da umidade. Nos ensaios, fixou-se a concentração do resíduo em $2 \mathrm{~g} / \mathrm{L}$ e variouse a concentração de peróxido de hidrogênio $\left(\mathrm{H}_{2} \mathrm{O}_{2}\right.$ P.A. $35 \%$ v/v) entre 500, 250 e $100 \mathrm{mg} / \mathrm{L}$. Considerou-se o início do processo oxidativo a partir da adição de solução de peróxido de hidrogênio. Também, realizaram-se ensaios somente com $\mathrm{H}_{2} \mathrm{O}_{2}$ nas concentrações de $100 \mathrm{e}$ $250 \mathrm{mg} / \mathrm{L}$. O efluente foi acidificado com solução 0,5 M de ácido clorídrico (HCl).

Tabela 1 - Composição química do resíduo

\begin{tabular}{ccccccccc}
\hline Componente & $\mathrm{H}_{2} \mathrm{O}$ & $\mathrm{FeT}$ & $\mathrm{Mn}$ & $\mathrm{P}$ & $\mathrm{SiO}_{2}$ & $\mathrm{CaO}$ & $\mathrm{Al}_{2} \mathrm{O}_{3}$ & $\mathrm{TiO}_{2}$ \\
\hline Percentual (\%) & 4,037 & 58,02 & 0,021 & 0,059 & 13,33 & 0,013 & 1,663 & 0,060 \\
\hline
\end{tabular}

Fonte: Aperam South America, 2017.

Alíquotas de $10 \mathrm{~mL}$ foram retiradas para determinação de Demanda Química de Oxigênio (DQO) em tempos previamente determinados (10, 20, 30 e 60 minutos de reação) para concentrações de $\mathrm{H}_{2} \mathrm{O}_{2}$ iguais a 250 e $100 \mathrm{mg} / \mathrm{L}$. Para $\left[\mathrm{H}_{2} \mathrm{O}_{2}\right]=500 \mathrm{mg} / \mathrm{L}$ as alíquotas foram recolhidas após 30 e 60 minutos de reação. As amostras retiradas tiveram a reação interrompida com a adição de $10 \mathrm{~mL}$ de solução de sulfito de sódio $\left(\mathrm{Na}_{2} \mathrm{SO}_{3}\right)$ em quantidade equimolar ao peróxido residual (Araújo, 2008; Gonçalves, 2016; Oliveira et al., 2000). Todas as amostras tratadas, se necessário, tiveram o $\mathrm{pH}$ corrigido para menor do que 3 , foram previamente filtradas e colocadas sob agitação de $1000 \mathrm{rpm}$ por um período de 2 horas, a fim de remover $\mathrm{Na}_{2} \mathrm{SO}_{3}$ residual, que interfere na análise de DQO (Wang et al. 2013).

As análises de DQO do efluente bruto e das amostras tratadas foram realizadas em triplicata, segundo método descrito pela American Public Health Association.

\section{RESULTADOS E DISCUSSÃO}

A água de lavagem coletada apresentou pH 9,88 $\pm 0,05$ e DQO=8288,89 $\mathrm{mgO}_{2} / \mathrm{L}$. O caráter alcalino do efluente deve-se, provavelmente, ao catalisador básico utilizado na reação de transesterificação. Gonçalves e colaboradores (2014) obtiveram considerável remoção na DQO de efluente real de biodiesel produzido por transesterificação alcalina utilizando óleo 


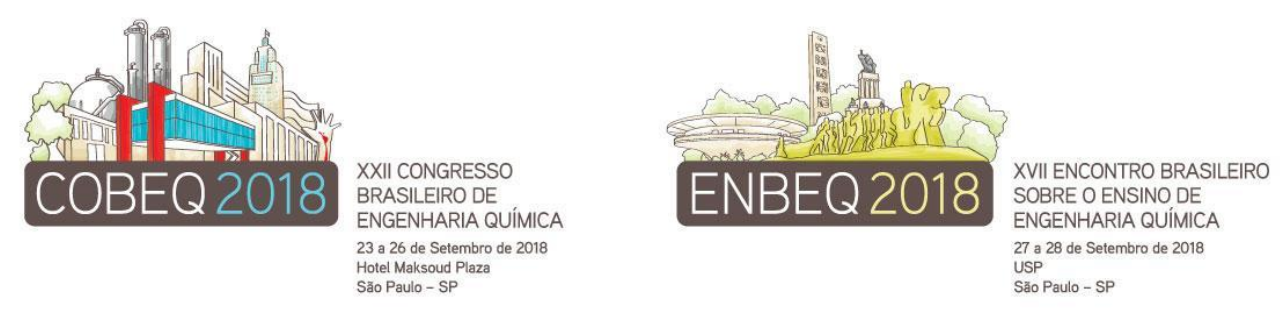

residual e etanol. Assim, neste trabalho analisou-se a DQO do efluente após acidificação, que foi de 7475,56 mgO $2 / \mathrm{L}$. Adotou-se a DQO pós acidificação como parâmetro no cálculo da eficiência da reação de Fenton e ensaios somente com $\mathrm{H}_{2} \mathrm{O}_{2}$. $\mathrm{O}$ fato da acidificação não ter sido relevante neste trabalho pode decorrer dos efluentes possuírem características diferentes, uma vez que Gonçalves et al. (2014) não citaram qual catalisador utilizado na produção do biodiesel e qual a água de lavagem foi tratada e, ainda, o álcool foi distinto entre os trabalhos.

Após acidificação, o pH das amostras foi de 2,88 \pm 0,07. Inicialmente, realizaram-se ensaios de Fenton para $\left[\mathrm{H}_{2} \mathrm{O}_{2}\right]=500 \mathrm{mg} / \mathrm{L}$, nos tempos de 30 e 60 minutos. Obteve-se queda na DQO de 75,8 e 93,4\%, respectivamente. Apesar do resultado satisfatório para o tempo reacional de 60 minutos, diminuiu-se a $\left[\mathrm{H}_{2} \mathrm{O}_{2}\right]$ para 250 e $100 \mathrm{mg} / \mathrm{L}$, bem como realizaram-se os ensaios de remoção da DQO nos tempos determinados, cujos resultados obtidos encontram-se na Figura 1.

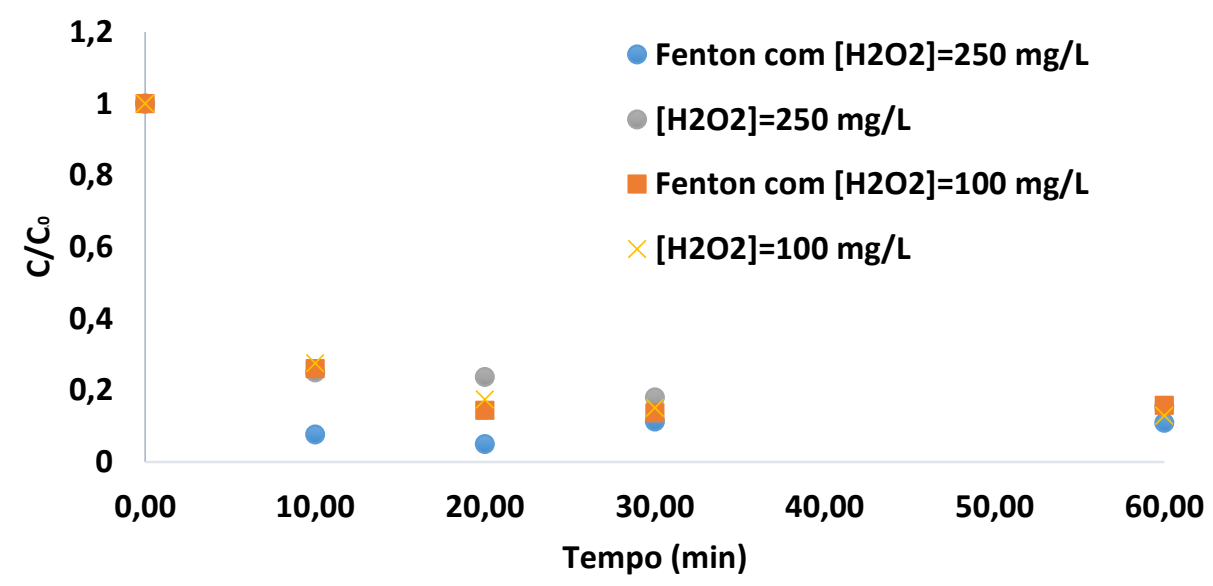

Figura 1 - Ensaios de remoção da DQO com $\mathrm{H}_{2} \mathrm{O}_{2}$ e com reação de Fenton Heterogênea.

$\mathrm{O}$ gráfico da Figura 1 mostra que a reação de Fenton com $\left[\mathrm{H}_{2} \mathrm{O}_{2}\right]=250 \mathrm{mg} / \mathrm{L}$, apresentou melhor resultado na remoção da DQO, que chegou a 92 e 95\%, em 10 e 20 minutos de reação, respectivamente. Essa melhoria nos percentuais de remoção, em comparação com a maior $\left[\mathrm{H}_{2} \mathrm{O}_{2}\right]$, de $500 \mathrm{mg} / \mathrm{L}$, pode ter ocorrido em razão da concentração do resíduo não favorecer a reação em excesso de $\mathrm{H}_{2} \mathrm{O}_{2}$, que por sua vez, ainda pode ter sequestrado radicais hidroxila. Assim, para $\left[\mathrm{H}_{2} \mathrm{O}_{2}\right]=500 \mathrm{mg} / \mathrm{L}$, faz-se necessário o aumento da área de superfície (concentração) do mineral (Araújo, 2008). Foi investigado o tratamento das amostras somente com $\mathrm{H}_{2} \mathrm{O}_{2}$ na mesma concentração, contudo o resultado não foi tão satisfatório se comparado em conjunto com o resíduo. Neste caso, observou-se queda gradual da DQO com o tempo, obtendo-se aos 60 minutos de reação eficiência de 84,5\%.

Para $\left[\mathrm{H}_{2} \mathrm{O}_{2}\right]=100 \mathrm{mg} / \mathrm{L}$, o ensaio de Fenton apresentou menores percentuais de remoção da DQO, sendo 73,9 e $85,6 \%$ para 10 e 20 minutos de reação, respectivamente. Quanto à amostra tratada somente com $\mathrm{H}_{2} \mathrm{O}_{2}$, também se observou aumento do percentual de remoção da DQO com o decorrer da reação, chegando a $87 \%$ aos 60 minutos.

Araújo (2008) estudou o uso de hematita no tratamento de soluções contendo corante reativo através de reação de Fenton Heterogênea. Em seu trabalho, constatou-se que em pH 2,5, o aumento da $\left[\mathrm{H}_{2} \mathrm{O}_{2}\right]$ propiciou maior percentual de remoção da DQO, enquanto que para 


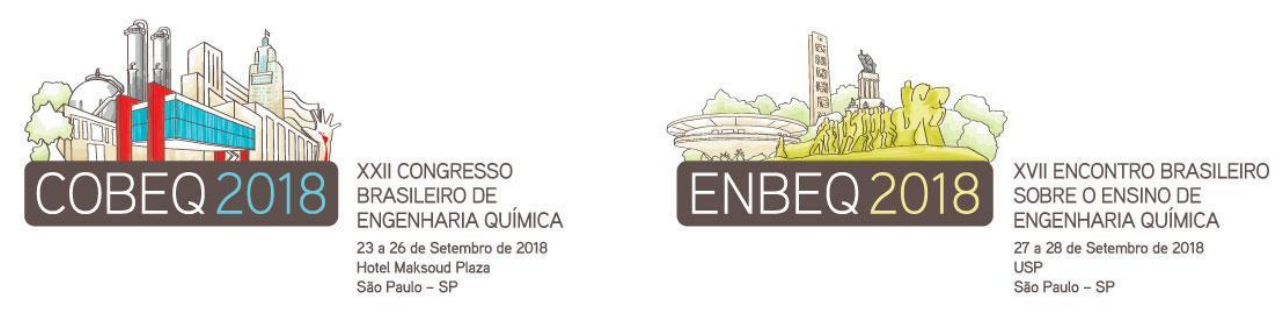

o mesmo pH, o aumento na concentração do resíduo melhorou consideravelmente somente a descoloração do efluente. No citado estudo, a condição favorável foi obtida para $\left[\mathrm{H}_{2} \mathrm{O}_{2}\right]=800$ $\mathrm{mg} / \mathrm{L}$ e $20 \mathrm{~g} / \mathrm{L}$ de concentração da hematita, em 120 minutos de reação. Neste trabalho, apesar de não ter sido contemplada a variação da concentração do resíduo, obtiveram-se melhores percentuais de remoção da DQO para reação de Fenton Heterogênea com $\left[\mathrm{H}_{2} \mathrm{O}_{2}\right]=250 \mathrm{mg} / \mathrm{L}$, em comparação com a concentração de peróxido de hidrogênio de 100 mg/L.

Através dos resultados obtidos, também se observou que para $\left[\mathrm{H}_{2} \mathrm{O}_{2}\right]=100 \mathrm{mg} / \mathrm{L}$, tanto a reação de Fenton Heterogênea quanto o ensaio somente com $\mathrm{H}_{2} \mathrm{O}_{2}$ apresentaram percentuais de remoção da DQO muito próximos nos tempos de amostragem. Neste caso, devido à menor $\left[\mathrm{H}_{2} \mathrm{O}_{2}\right]$, provavelmente os radicais hidroxila formados não foram suficientes para oxidar toda a matéria orgânica presente no efluente, seja na presença ou ausência do resíduo.

\section{CONCLUSÃO}

Com esse estudo verificou-se que a reação de Fenton Heterogênea utilizando pó de minério demonstrou bom potencial de remoção da DQO presente nas amostras de águas de lavagem de biodiesel. Foi obtida eficiência superior a $90 \%$ em 10 minutos de reação, para $\left[\mathrm{H}_{2} \mathrm{O}_{2}\right]=250 \mathrm{mg} / \mathrm{L}$ e $2 \mathrm{~g} / \mathrm{L}$ do pó de minério, sendo essa a relação ótima obtida entre concentrações de $\mathrm{H}_{2} \mathrm{O}_{2}$ e resíduo.

\section{REFERÊNCIAS}

ARAÚJO, F. V. D. F, Estudo do processo Fenton Heterogêneo utilizando hematita $\left(\mathrm{Fe}_{2} \mathrm{O}_{3}\right)$ como catalisador na descoloração de soluções de corante reativo. 2008. 183f. Tese (Doutorado em Tecnologia dos Processos Químicos e Bioquímicos) - Escola de Química da Universidade Federal do Rio de Janeiro, Rio de Janeiro, 2008.

BRITO, G. F. S. Avaliação dos processos Fenton e foto-Fenton no tratamento da água de lavagem do biodiesel de soja. 2015. 86f. Dissertação (Mestrado em Química) - Universidade de Brasília, Brasília, 2015.

GONÇALVES, L. O. et al. Tratamento do efluente gerado na produção de biodiesel por processo oxidativo avançado: Reagente de Fenton. In: XX Congresso Brasileiro de Engenharia Química, Florianópolis, 2014.

GONÇALVES, B. R, Tratamento de efluente da produção de biodiesel utilizando processos físico-químicos e reações de Fenton. 2016. 99f. Dissertação (Mestrado em Química) Universidade Federal de Uberlândia, Uberlândia, 2016.

OLIVEIRA, M. C. et al.,Sistema de injeção em fluxo espectrofotométrico para monitorar peróxido de hidrogênio em processo de fotodegradação por reação foto-Fenton. Química Nova, v. 24, p. 188-190, 2001.

WANG, Y., LI, W. \& IRINI, A., A novel and quick method to avoid $\mathrm{H}_{2} \mathrm{O}_{2}$ interference on COD measurement in Fenton system by $\mathrm{Na}_{2} \mathrm{SO}_{3}$ reduction and $\mathrm{O}_{2}$ oxidation. Water Sciense \& Technology, p. 1529-1535, 2013. 